\title{
Immediate implant placement in anterior teeth with grafting material of autogenous tooth bone vs xenogenic bone
}

\author{
Dong $\mathrm{Wu}^{1+}$, Lin Zhou $^{1 \dagger}$, Jichao Lin², Jiang Chen ${ }^{1}$, Wenxiu Huang ${ }^{1}$ and Yonghui Chen ${ }^{3^{*}}$ (D)
}

\begin{abstract}
Background: The aim of the study was to compare the efficacy of the autogenous tooth bone and xenogenic bone grafted in immediate implant placement with bone defect.

Methods: Thirty patients whose compromised anterior teeth need immediate implant placement were enrolled. Autogenous tooth bone made from the extracted teeth by chair-side or the xenogenic bone were used to repaired bone defect. Clinical examination, radiographic assessment about the horizontal bone change in the level of $0 \mathrm{~mm}$, $3 \mathrm{~mm}$ and $6 \mathrm{~mm}$ below the implant neck and the marginal bone loss were made immediately, 6 and 12 months after implant placement. Questionnaire of the feelings about the surgery were made at the time of removing the sutures.

Results: All implants achieved the success criteria without any complications at the follow-up period. The percent of the horizontal bone change and the marginal bone loss at 6 and 12 months were almost the same between two groups $(P>.05)$. The horizontal bone loss at the first or the latter 6 months was almost the same $(P>.05)$. But the horizontal bone loss at the $6 \mathrm{~mm}$ level was less than the $0 \mathrm{~mm}$ and $3 \mathrm{~mm}$ levels at 6 and 12 months $(P<.05)$.

Meanwhile patients seem more satisfied with the autogenous tooth bone derived from the questionnaire.

Conclusion: The bone volume change in the facial part of the implant after immediate placement is almost the same between two groups. Providing clinical evidence that the autogenous tooth bone made from compromised tooth can be an acceptable bone graft material.
\end{abstract}

Keywords: Autogenous tooth, Bone graft, Immediate implant placement, Implant dentistry

\section{Background}

With the development of dental implant technology and biomaterials, dental implants have become the preferred treatment for dentition and edentulous patients. Within the development of decades, several strategies of implant placement had been developed. Among them, the immediate implant placement in anterior teeth had been widely accepted after it been introduced in the late 1970s by Schulte and Heimke [1], because it can avoid the buccal bone resorption, shorten the period of

\footnotetext{
* Correspondence: chy1501@163.com

${ }^{\dagger}$ Dong Wu and Lin Zhou should be considered joint first authors, this two authors contributed equally to this paper.

${ }^{3}$ Department of Stomatology, Zhangzhou Affiliated Hospital of Fujian

Medical University, Zhangzhou 363000, Fujian, China

Full list of author information is available at the end of the article
}

treatment time, and avoid the lack of teeth due to the provisional restoration [2].

Bone deficiency happened among in over half of implantation sites [3]. Meanwhile, there are half of immediate implant placement in anterior teeth need bone augmentation, due to the defect of buccal wall which may cause by trauma, apical periodontitis and periodontitis [4]. Bone augmentation cannot be carried out without bone graft materials. Autogenous bone, allogenic bone, xenogenic bone, and alloplastic materials are bone graft materials that are presently used in dental clinic. Autogenous bone graft material is considered as the golden standard since it's capable of osteogenesis, osteoinduction, and osteoconduction. However, the generation of donor area which cause secondary defect, more trauma and complexed, and the limited harvest 
amount of collected bone restricted its application [5]. Allogenic bone and xenogenic bone may lead to infection or immune rejection. Limited osteogenic effect, high cost of treatment and low degree of patient's acceptance restrict their clinical application [6].

In recent years, some cases reported that autogenous tooth bone graft material made from compromised teeth was applied in bone deficient areas and achieved a good clinical efficacy [7-11]. Especially in the case of immediate extraction implant placement, the compromised teeth can be used as a bone graft material which is more accepted by patients. Autogenous tooth bone graft material was first development in 2008 and used as a bone graft material in guided bone regeneration [12]. As we know that the components of tooth are very similar to the alveolar bone. The total inorganic content, organic content and water of the enamel and dentin is $95,0.6,4$ and $70 \%, 20,10 \%$ respectively, which is similar to those contents of 65,25 , $10 \%$ in alveolar bone [13]. The histological outcomes of the discarded teeth after demineralization are similar to autogenous bone grafts, which make it be the perfect bone graft materials for its osteoconductive and osteoinductive property [8]. Thought the clinical outcomes of the autogenous tooth bone graft materials had been widely reported, but the comparison with other bone graft materials is still rare.

The aim of our present retrospective study was to compare the clinical effect of the autogenous tooth bone graft materials with the xenogenic bone graft materials (Bio-Oss) in bone regeneration of immediate extraction implant placement with a defect of labial bone wall.

\section{Methods}

\section{Patient selection}

This was a retrospective observational study of patients, whose anterior teeth need to be extracted with a defect of labial bone, need immediate implant placement with bone augmentation using bone graft material. From March 2016 to May 2017, 30 patients (12 women; 18 men), with a mean age of $48 \pm 16.7$ years (range 19 to 67 years) were collected from department of oral and maxillofacial implant research center, Affiliated Stomatological Hospital of Fujian Medical University. All patients were informed about the surgical and restoration treatment procedure. The study design was performed in accordance with the Helsinki Declaration (revised in 2008).

The inclusion criteria were as follow: (1) Anterior teeth need to be extracted with a defect of labial bone (horizontal or vertical bone defect). (2) the teeth without acute inflammation. (3) Without uncontrolled systemic disease which is not suitable for implantation. (4) Good systemic and oral health. And the exclusion criteria were: (1) Heavy smoker (> 10 cigarettes/day). (2) Acute inflammation in the site of implantation and adjacent tissue. (3) A history of radiotherapy in the head or neck region. (4) With systemic disease like uncontrolled diabetes mellitus, coagulation disorders, alcohol or drug abuse not suitable for implantation.

\section{Preoperative work-up}

All patients perform general oral examination and CBCT examination to observe the structure of the teeth which need to be extracted and the labial bone before surgery. Then we measured the available bone width and bone height to determine the treatment program and reach consensus with patients. All patients got the serial of professional oral hygiene with scaling and root planning 2 weeks before surgery. For the prevention of infection and better plaque control, all patients were given antibiotic 3 days before surgery and mouthrinsed with $0.2 \%$ chlorhexidine 1 week before surgery. At the same time, surgeon measured the $\mathrm{CBCT}$ to precisely assess the width, the depth and the defect of the labial bone, in order to perform better implant placement and choose the most appropriate implant.

\section{Autogenous tooth bone graft preparation}

All the preparation of autogenous tooth bone graft material was done by the same dentist who was well skilled with this technology. Autogenous tooth bone graft material derived from tooth which need to be extracted without the retention value, and prepared following the instructions of vacuum ultrasonic autoclaved bone preparation equipment (VacuaSonic ${ }^{\oplus}$, Korea). Autogenous teeth without retention value were extracted with a minimally invasive tooth extraction device, under routine local infiltration anesthesia or block anesthesia with Primacaine ${ }^{\circ}$ (4\% Articaine, $1 / 100000$ adrenaline, ACTEON) 30mins before surgery. The residual periodontal ligament on root surfaces was removed. Caries and restorations were removed by the grinding needle. Then the tooth was crushed into debris by a hammer in an iron container, meanwhile the dental pulp or canal filling material was removed. The size of the debris is determined by a sieve. At last the bone debris was put into a vacuum ultrasonic autoclaved bone preparation equipment with different solution according to the manufacture. After demineralization, peracetic acid sterilization and rinse, autogenous tooth bone graft material was prepared eventually as it showed in the Fig. 1.

\section{Surgical and prosthetic Proceduce}

All the surgeries were performed by the same surgeon with more than 25 years of experience. Tooth extraction was made under local anesthesia with Primacaine ${ }^{\circ}(4 \%$ Articaine,1/100000 adrenaline, ACTEON) before surgery. Then the full-thickness midcrestal incision and vertical releasing incision in distal side were made, vertical 


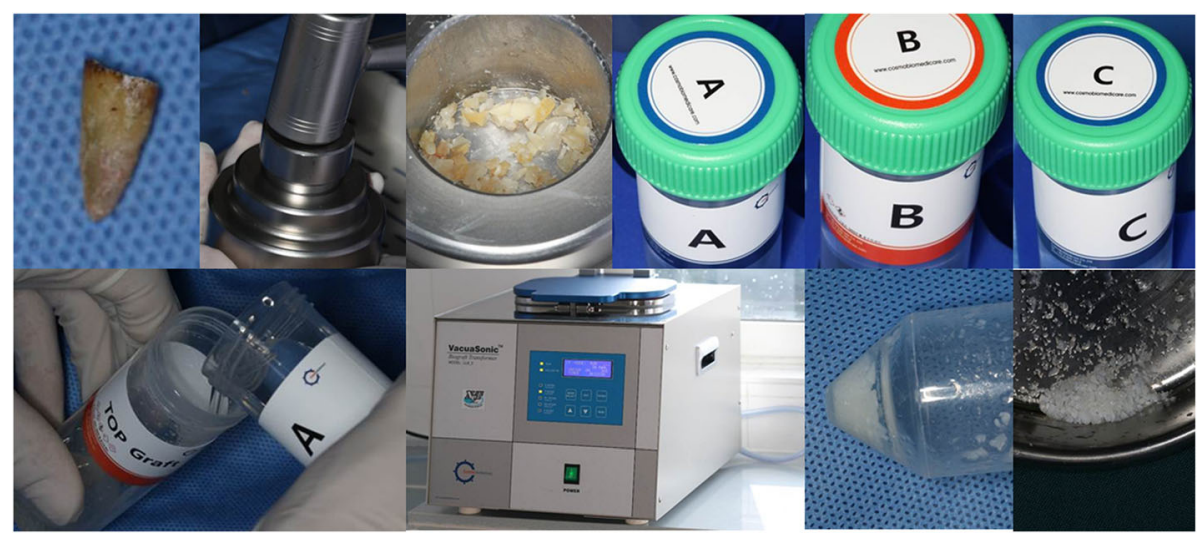

Fig. 1 Chairside preparation of autogenous tooth bone graft materials. Autogenous tooth without retention value was removed with minimally invasive extraction. Surface preparation and pretreatment were performed on the teeth. The tooth was crushed into debris. Bone powder was prepared. Demineralization, sterilization and rinse were performed for autogenous tooth bone graft materials

releasing incision in mistal side was made if necessary. The extraction socket and the labial bone defect were exposed by buccal and palatal flap reflection. Inflammatory granulation tissue was removed before hole preparation. The implant position was marked on the palatal bone wall of the extraction socket with a small round drill (diameter of $2.0 \mathrm{~mm}$ ). Subsequently, pioneer drill was used to make the right implant depth which was 3$4 \mathrm{~mm}$ below the gingival level of final restoration and implant position which was at the centerperdetermined mesiodistal width with a minimal distance of $2 \mathrm{~mm}$ from the adjacent tooth and a few palatal side of the buccal and palatal aspect. Then the drills were used to expand the hole to the final size step by step, and insert the screw type implant with the cover screw placed. The autogenous tooth bone (atuoBT) or the xenogenic bone (xenoB, Geistlich Bio-Oss) were used to filled the gap between the facial bone wall and the implant and the defect of the facial bone to reach the enough buccal bone supported, and then the graft materials were covered with absorbable barrier membranes(Bio-Gide, Geistlich). Finally, the flap was repositioned and sutured. The brief process of the surgery is showed in Fig. 2. According to implant routine postoperative medical advice, a certain amount of antibiotics were given to prevent wound infection and excessive bleeding. After 4 mouths healing, the prosthetic procedure was performed with a titanium abutment and a zirconium dioxide crown. Patients underwent $\mathrm{CBCT}$ examination immediately, 6 months and 1 year after surgery.

\section{Outcome measurements Implant success}

The implant success criteria in our study was based on the criteria of Albrektsson, Zarb, Worthington and Eriksson(1986) and of Buser, Weber and Lang(1990). The following are the criteria of the implant success: the absence of mobility, the absence of acute or chronic peri-implant infection, the absence of radiolucency around the implant, without pocket probing depth (PPD) $\geqq 5 \mathrm{~mm}$, and without vertical bone loss $\geqq 1.5 \mathrm{~mm}$ in the first year. The cases will be defined as failure if it can't reach any one of the success criteria.

\section{Clinical assessment}

Swelling, wound dehiscence and other adverse events were observed at 3 days and 7 days after implant placement. The guided bone regeneration using different graft

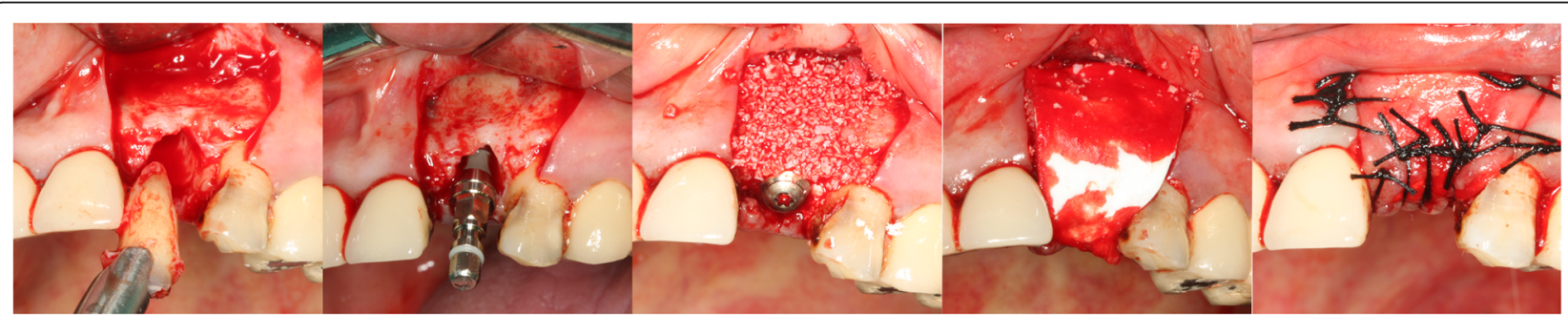

Fig. 2 Surgical proceduce of the implant placement and bone grafting 
materials regard as failure when the following clinical feature arisen: emerging of the fistula, the particle of the bone graft material flow out from the fistula or mucosal dehiscence, and the chronic inflammation.

\section{Radiographic assessment}

All the patients were measured by CBCT scanning before implant placement, immediately after implant placement, 6 months and 12 months follow-up. And all the measurements were done by one dentist who did not know which group was. Marginal bone level and horizontal bone change at the facial side of implant were measured. The centre of the implant was set as a vertical reference line in the $\mathrm{CBCT}$ image and all the measured points were perpendicular to it. We measured the labial horizontal bone width perpendicular to the vertical line of the implant surface at the implant neck level or the top of the buccal bone (which is regarded as $0 \mathrm{~mm}$ ), 3 $\mathrm{mm}$ and $6 \mathrm{~mm}$ apical to the implant neck level as it shown in Fig. 3. The stability of the labial horizontal bone was evaluated by the percent of the horizontal bone loss. And the percent of the horizontal bone loss at each time point and each measured point were calculated by the following formula: (width of base line - width of following-up time)/ width of base line. Meanwhile the marginal bone level (MBL) at the implant neck

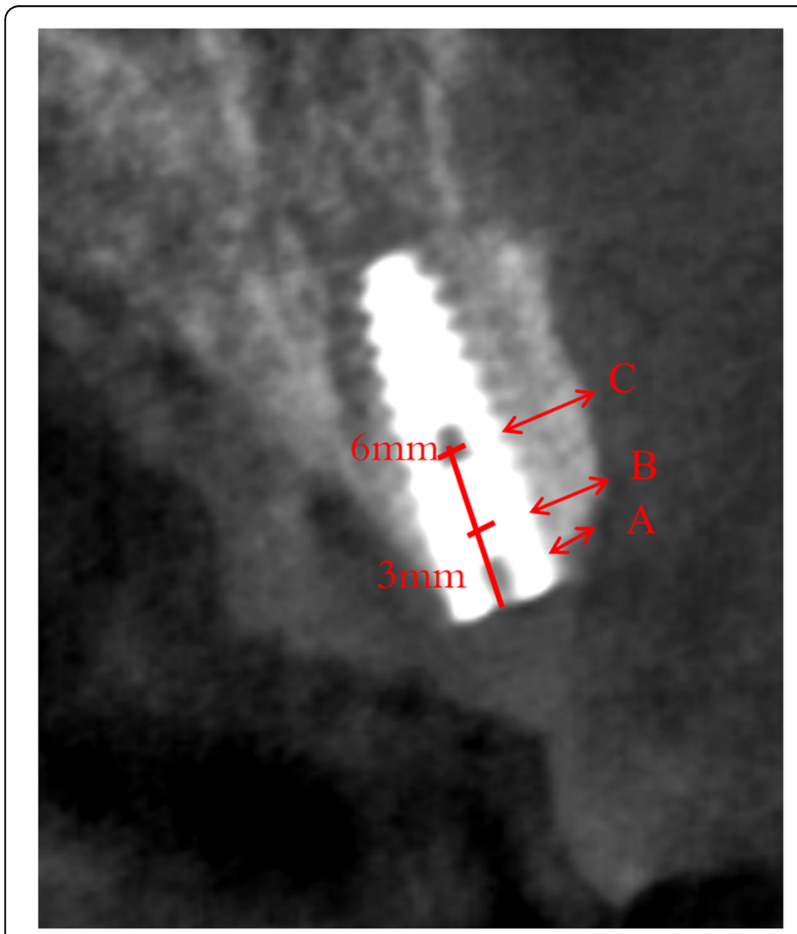

Fig. 3 The measured point of facial bone. a represent the bone width at the level of implant neck or the top of the buccal bone. $\mathbf{b}$ and $\mathbf{c}$ represent the bone width of the $3 \mathrm{~mm}$ and $6 \mathrm{~mm}$ below the implant neck level level was measured at different following-up time according to the CBCT image.

\section{Patient satisfaction evaluation}

Patient satisfaction was evaluated by a questionnaire based on the Visual Analog Scales (VAS 0-10), which is focused on the pain, swelling, satisfaction of the surgery process. All patients answer the questionnaire at the time of removing the suture. The questionnaire was show in Additional file 1.

\section{Statistical analysis}

The data about the percent of the horizontal bone loss, marginal bone level at different following-up time and between different bone graft materials were compared with each other using the Independent-Samples t-test with the SPSS 22.0 software. So did the results of the questionnaire. The percent of the horizontal bone loss at different measure level were compared with each other using one-way ANOVA. $P$ values $<0.05$ were defined as statistically significant.

\section{Results}

\section{Basic information of patients}

In our study, the total of 30 patients were included (12women/ 18men, mean age: $40.43 \pm 13.58$ years). Among the 30 implants, 15 belonged to the group of autogenous tooth bone graft and the rest belonged to the group of xenogenic bone graft. The implant location and the basic information of the patients were detailed in the Table 1.

\section{Implant success}

All the implant in the both group reach the success criteria of our paper mentioned above during the entire observation period. Neither the implants nor the bone graft materials had any biological and mechanical complications, like peri-implantitis and infection during the follow-up period.

\section{Clinical observation}

We observed whether the pain, swelling and other complaint happened in the patient at the day 3 and 7 after surgery. Both two groups had different level of pain and swelling at the day 3 and 7 after surgery. But none of the 30 patients had the clinical manifestation of infection and wound dehiscence.

\section{Radiographic assessment}

The width of the horizontal bone in the level of $0 \mathrm{~mm}, 3$ $\mathrm{mm}$ and $6 \mathrm{~mm}$ at the 6 months and 12 months in the different groups were measured. And the percent of the horizontal bone change was calculated according to the formula above. The percent of the horizontal bone 
Table 1 Basic information of the involved patients

\begin{tabular}{|c|c|c|c|c|c|c|}
\hline \multirow{2}{*}{$\begin{array}{l}\text { Patients } \\
\text { No. }\end{array}$} & \multicolumn{3}{|c|}{ Autogenous tooth bone } & \multicolumn{3}{|c|}{ Xenogenic bone (Bio-Oss) } \\
\hline & Age Ranges & Tooth extraction site & Implant brand and sizes (mm) & Age Ranges & Tooth extraction site & Implant brand and sizes ( $\mathrm{mm}$ ) \\
\hline 1 & $60-70$ & 12 & Straumann $3.3^{*} 13$ & $20-30$ & 12 & BEGO $3.25 * 13$ \\
\hline 2 & $40-50$ & 21 & BEGO $4.1^{* 13}$ & $30-40$ & 21 & BEGO $3.25^{*} 13$ \\
\hline 3 & $20-30$ & 22 & BEGO $3.25 * 11.5$ & $30-40$ & 22 & BEGO $3.25^{*} 13$ \\
\hline 4 & $20-30$ & 12 & BEGO $3.25^{*} 13$ & $20-30$ & 12 & Straumann $3.3^{*} 13$ \\
\hline 5 & $30-40$ & 21 & BEGO $3.75^{*} 13$ & $50-60$ & 21 & BEGO $3.75^{*} 13$ \\
\hline 6 & $60-70$ & 12 & Straumann $3.3^{*} 13$ & $40-50$ & 21 & Straumann $3.3^{*} 13$ \\
\hline 7 & $20-30$ & 12 & Straumann $3.3^{*} 13$ & $50-60$ & 22 & BEGO $3.25^{*} 13$ \\
\hline 8 & $10-20$ & 13 & $\mathrm{BEGO} 4.1^{* 13}$ & $50-60$ & 23 & BEGO $3.75^{*} 13$ \\
\hline 9 & $30-40$ & 12 & BEGO $3.25 * 11.5$ & $50-60$ & 11 & Straumann $3.3^{*} 13$ \\
\hline 10 & $40-50$ & 21 & Straumann $3.3^{*} 13$ & $30-40$ & 22 & Straumann $3.3^{*} 13$ \\
\hline 11 & $40-50$ & 21 & BEGO $3.75^{*} 15$ & $40-50$ & 11 & BEGO $3.75^{*} 13$ \\
\hline 12 & $30-40$ & 13 & MIS $3.75^{*} 13$ & $30-40$ & 21 & BEGO $3.25 * 13$ \\
\hline 13 & $50-60$ & 22 & BEGO $3.25^{*} 13$ & $60-70$ & 21 & BEGO $3.75^{*} 11.5$ \\
\hline 14 & $40-50$ & 23 & MIS $3.75^{*} 13$ & $50-60$ & 11 & BEGO $3.75 * 13$ \\
\hline 15 & $20-30$ & 21 & BEGO $3.75^{*} 13$ & $30-40$ & 11 & BEGO $3.75^{*} 13$ \\
\hline
\end{tabular}

change at 6 months in the level of $0 \mathrm{~mm}, 3 \mathrm{~mm}$ and 6 $\mathrm{mm}$ were $(4.06 \pm 1.53),(4.45 \pm 1.16)$ and $(2.40 \pm 1.11)$ in the group of autoBT, and $(4.01 \pm 1.45),(3.66 \pm 1.49)$ and $(2.54 \pm 1.36)$ in the group of xenoB. And the percent of the horizontal bone change at 12 months in the level of $0 \mathrm{~mm}, 3 \mathrm{~mm}$ and $6 \mathrm{~mm}$ were $(7.99 \pm 5.29),(6.94 \pm 2.70)$ and $(4.58 \pm 1.91)$ in the group of autoBT, and $(7.18 \pm$ $2.62),(6.31 \pm 2.76)$ and $(5.15 \pm 2.36)$ in the group of xenoB. The change of the horizontal bone at 6 and 12 months in the level of $0 \mathrm{~mm}, 3 \mathrm{~mm}$ and $6 \mathrm{~mm}$ between the two groups had no significant different as it showed in the Fig.4. Meanwhile the change of the horizontal bone at the group of autogenous tooth bone and the xenogenic bone in the level of $0 \mathrm{~mm}, 3 \mathrm{~mm}$ and $6 \mathrm{~mm}$ between the first 6 months and latter 6 months also had no significant different as it showed in the Fig.5. The change of the horizontal bone at 6 months and 12 months in the group of autoBT at the level of $6 \mathrm{~mm}$ is significant lower than the level of $0 \mathrm{~mm}$ and $3 \mathrm{~mm}$, but there was no different between the level of $0 \mathrm{~mm}$ and 3 $\mathrm{mm}$. And the change of the horizontal bone at 6 months in the group of xenoB in the level of $6 \mathrm{~mm}$ was significant lower than the level of $0 \mathrm{~mm}$ and $3 \mathrm{~mm}$, but only the $0 \mathrm{~mm}$ level was significant higher than the $6 \mathrm{~mm}$. This result showed in the Fig.6.

Meanwhile the marginal bone loss was measured by CBCT image at 6 and 12 months. The marginal bone loss at 6 months were $(0.11 \pm 0.05) \mathrm{mm}$ and $(0.13 \pm 0.04)$ $\mathrm{mm}$ in the group of autoBT and xenoB respectively. And the marginal bone loss at 12 months were $(0.38 \pm 0.1)$ $\mathrm{mm}$ and $(0.31 \pm 0.12) \mathrm{mm}$ in the group of autoBT and
xenoB respectively. Both the different had no statistic significant as it showed in Fig. 7.

\section{Patient satisfaction}

All the patients answered the questionnaire at the time of removing the suture. The value of the pain, swelling and the satisfaction were $(2.60 \pm 1.12),(3.00 \pm 1.00)$ and $(7.87 \pm 0.92)$ in the group of autogenous tooth bone, and (4.00 \pm 1.13$),(4.47 \pm 1.19)$ and $(8.07 \pm 1.03)$ in the group of xenogenic bone respectively as it shows in the Table 2 . The pain and the swelling in the group of autogenous tooth bone were lower than the group of xenogenic bone, but the satisfaction of the surgery process is almost the same. The value in pain and swelling showed statistically significant difference as the Fig. 8 shown.

\section{Discussion}

In the present retrospective study, the autogenous tooth bone graft which was made by the extracted tooth chairside were successful used in the immediate implant placement in the fresh socket with facial bone defect. The protocol of the immediate implant placement using different bone graft material had been well evaluated in some systematic reviews $[2,14]$. And the protocol of immediate implant placement in fresh extraction socket may help to maintain the bone and soft tissue stable, enhancing the survival of the implant, shorten the treatment time and achieve patients' satisfaction [15].

But in many cases, there was a defect in the facial bone of the compromised teeth in the esthetic zone, and the bone graft is needed after implant placement. In the 
6 months follow-up

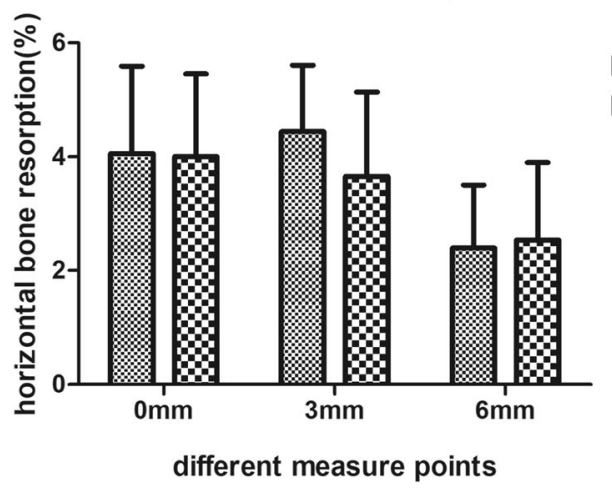

12 months follow-up

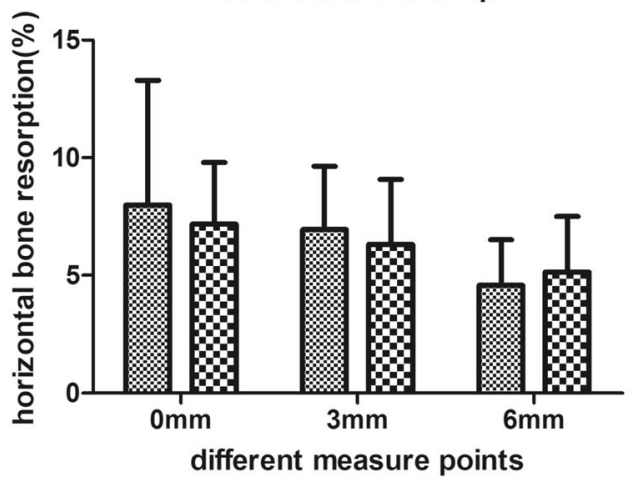

Fig. 4 The change of the horizontal bone at 6 and 12 months in the level of $0 \mathrm{~mm}, 3 \mathrm{~mm}$ and $6 \mathrm{~mm}$ between the autogenous tooth bone and xenogenic bone

present study, a total of 30 implant had been inserted into fresh socket with facial bone defect, half of it using autogenous tooth bone graft material and the rest of it using xenogenic bone (Bio-Oss). Neither the implant nor the graft material fail to reach the success criteria. The result consistent with other clinic studies. As patricia et al. reviewed that the mean implant survival rate was $97.7 \%$ while using the autogenous tooth bone as a graft material with a limited number of cases [13]. Also in other recent systematic review the implant survival rate using bone graft material were higher than $90 \%$ (range from 90 to 100\%) [16, 17]. Meanwhile, many studies had shown that Autogenous tooth bone graft materials have been applied for lateral sinus floor elevation, guided bone regeneration, alveolar bone preservation and other bone augmentation surgery [18], and show high bone formation activity and excellent biocompatibility [19]. The chemical composition of the teeth, especially dentin, closely approximates bone tissue. Dentin is rich in bone morphogenetic protein (BMP) which can promote bone marrow mesenchymal stem cell differentiation and accelerating osteogenesis [20].
The dentin consists of low crystalline hydroxyapatite similar to bone tissue, compared to the high crystalline enamel of hydroxyapatite structure. Meanwhile, previous studies also showed that the enamel could not be easily degraded by osteoclasts because of its highly mineralized calcium phosphate crystals, resulting in the difficulty of osteogenesis factors release such as BMPs and the delay of BMSCs migration, adhesion and differentiation on the material surface [21]. Hence, the osteoinductivity and osteoconductivity of the enamel and dentin make the autogenous tooth bone a perfect bone graft material and high success rate.

We measured the different level of the implant buccal bone width at different follow-up time to observed the stability of the horizontal bone. As we can see from the Figs 4, 5 and 6 about the change of the horizontal bone, there is no statistic difference between the two bone graft materials in three different measured level at the 6 months and 12 months follow-up period, and there is no statistic difference between the first and latter 6 months follow-up at two different bone graft material in three different measured levels. These results indicated that 


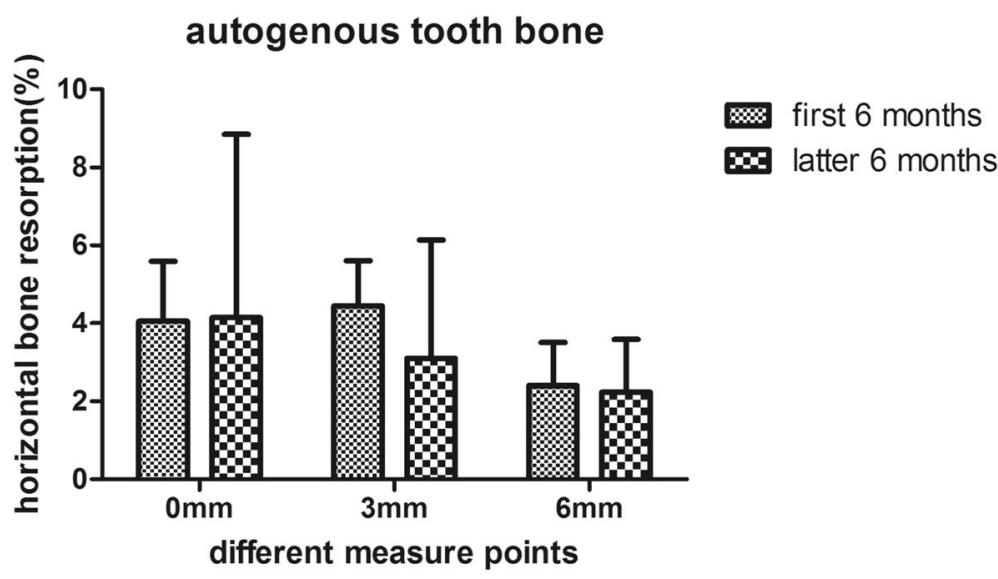

xenogenic bone

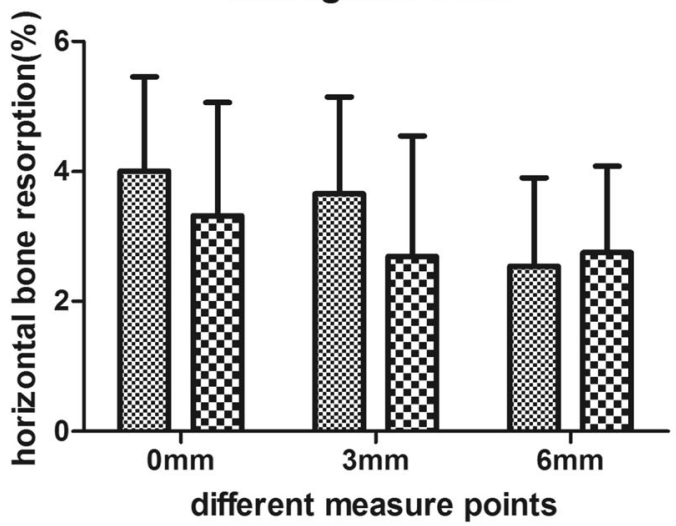

Fig. 5 The change of the horizontal bone at the group of autogenous tooth bone and the xenogenic bone in the level of $0 \mathrm{~mm}$, $3 \mathrm{~mm}$ and 6 $\mathrm{mm}$ between the first 6 months and latter 6 months

the horizontal bone loss in the autogenous tooth bone group is almost the same with the xenogenic bone in three measured levels at the 12 months following up and the horizontal bone loss at first and latter 6 months is also the same. But the horizontal bone loss at the level of $6 \mathrm{~mm}$ was much more than the level of $0 \mathrm{~mm}$ and 3 $\mathrm{mm}$ at the different follow-up time and different bone graft material, while the level of $0 \mathrm{~mm}$ is the same with the level of $3 \mathrm{~mm}$. We can drive from the result that the apical bone may be more stable than the marginal bone. All this percent of the horizontal bone loss was accepted, and was consensus with other research. Francesco et al. reported that the volumetric tissue changes after immediate extraction placement in the esthetic area can be minimized by a provisional restoration and bone graft inserted simultaneously with implant placement [22]. And Fabio's research proved that the protocol of flap approach would affected the bone volume changes in the immediate implant placement, and the reduction of bone width is almost $10 \%$ in the first 6 month [23].
Marginal bone is significant important for the facial gingiva of an implant, and it is also an important clinical parameter for the implant long term success. Overall, the marginal bone loss in the two groups ranging from 0.02 to 0.59 which was accepted by the clinical. And the marginal bone loss in the immediate implant placement using autogenous tooth bone and xenogenic bone were almost the same, which means the marginal bone level or the gingiva level was stable in the two bone graft materials. Many other clinical studies also showed that the implant placement in the fresh socket with GBR had an acceptable marginal bone loss [24, 25]. The Eugenio et al. indicated that the mean marginal bone loss was $0.67 \pm 0.40 \mathrm{~mm}$ (ranging from $0 \mathrm{~mm}$ to $1.6 \mathrm{~mm}$ ) in the immediate implant placement with the follow-up of 4 years [26]. And some characteristics of the implant like tapered, platform-switch, laser-microtextured would affect the marginal bone level. Iorio-Siciliano $\mathrm{V}$ et al. reported that implants with a laser-microtextured collar can 

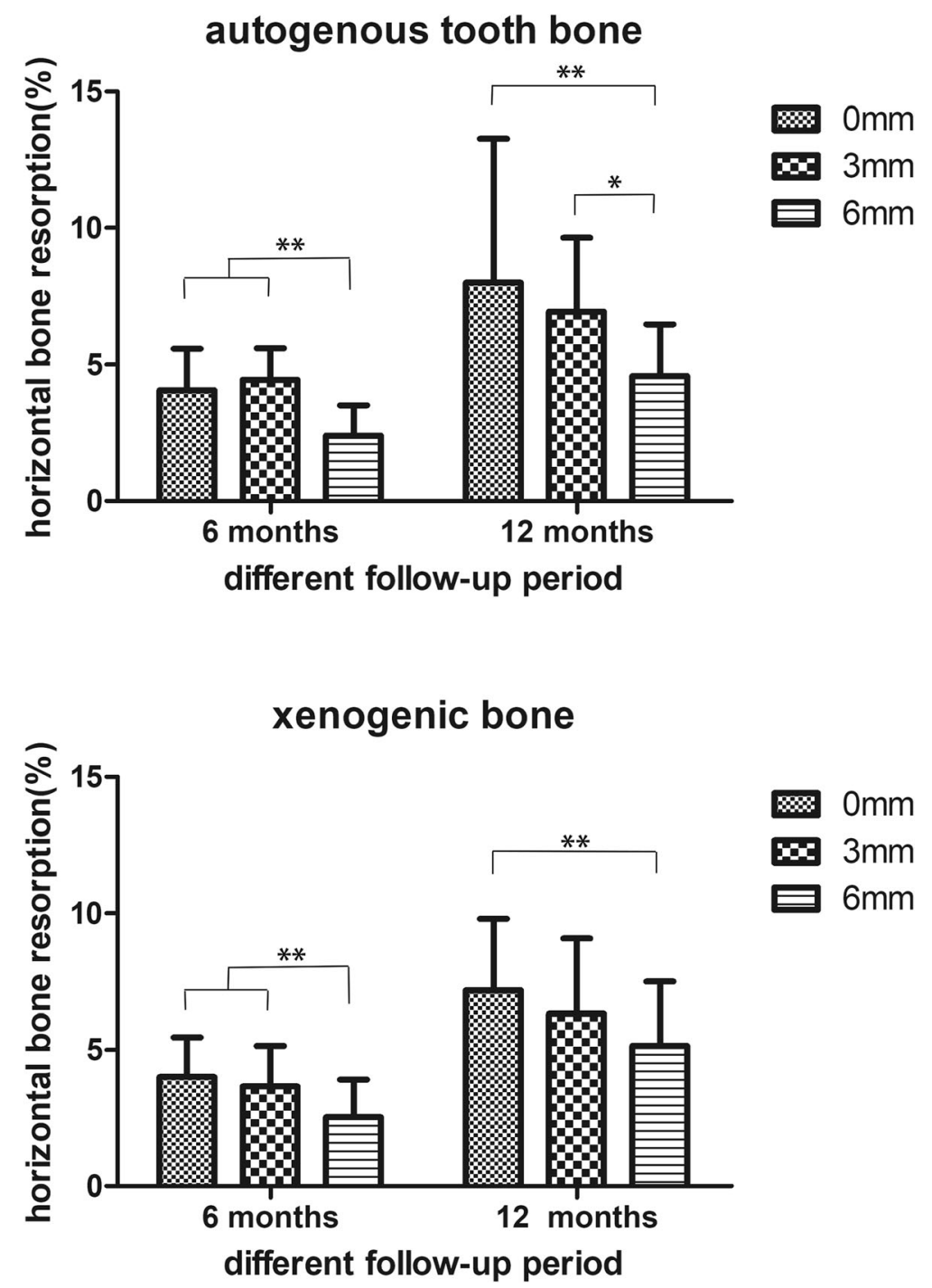

Fig. 6 The change of the horizontal bone at 6 months and 12 months in the group of autoTB and xenoB between the level of $0 \mathrm{~mm}, 3 \mathrm{~mm}$ and $6 \mathrm{~mm}$. ** represent $P$ values $<0.05,{ }^{*}$ represent $P$ values $<0.1$

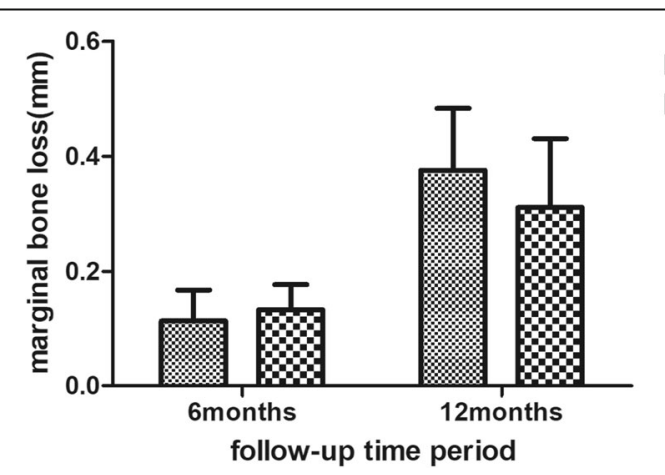

Fig. 7 The marginal bone loss at 6 months and 12 months in the group of autoBT and xenoB 
Table 2 The questionnaire of patients with different bone graft materials

\begin{tabular}{lllll}
\hline Questionnaire & Graft materials & Number & Mean & SD \\
\hline Pain & Autogenous tooth bone & 15 & 2.6000 & 1.12122 \\
& Xenogenic bone & 15 & 4.0000 & 1.13389 \\
Swelling & Autogenous tooth bone & 15 & 3.0000 & 1.00000 \\
& Xenogenic bone & 15 & 4.4667 & 1.18723 \\
\multirow{2}{*}{ Satisfaction } & Autogenous tooth bone & 15 & 7.8667 & 0.91548 \\
& Xenogenic bone & 15 & 8.0667 & 1.03280 \\
\hline
\end{tabular}

reduce the loss of marginal bone compared with tradition implant [27]. Iorio-Siciliano $\mathrm{V}$ et al. also reported that platform-switch can maintained marginal bone level [28]. There are 22 implants with the platform-switch in the 30 cases of the present study, which may help to reduce the loss of the marginal bone.

In the present study, the results of the questionnaire about the pain and swelling seems better in the group of the autogenous tooth bone graft material. This indicated that GBR with the autogenous tooth bone may cause less inflammatory reactive. Because the xenogenic bone grafted in the bone defect can be regard as a foreign substance insert into body, which can generate an immune and inflammatory reaction and it can be referred to as "osteoimmunology" [29, 30]. After the bone graft material inserted in the bone defect, the immune cell like macrophage will secrete pro-inflammatory cytokines as TNF- $\alpha$, IF-1, which caused a transient abnormal enlargement of the operative region [31]. Autogenous tooth bone is consisted of demineralized dentin matrix (DDM) largely which is demineralized from dentin, a mainly structure of teeth [32]. The DDM which is the internal stuff may arouse less auto-immunity, therefore the less swelling and pain happened. This is the hypothesis based on the osteoimmunology, the underlying reason still need to be exposed by molecular mechanism research. The auto-suggestion of the patients about the graft bone is part of themselves may ben benefit the postoperative reactions.

\section{Limitations}

The limitations of this study: the clinical observation period was 12 months which is not long enough to observe the long-term stability of the grafted bone. And the cases were done three or 4 years age, so the design the flap and the selection of the surgical consumables like the suture may be behindhand. The sample size of the research may not enough for a rigid statistical analysis. Thought the measurement was done by one dentist, the subjective bias was inevitable.

\section{Conclusion}

1. Immediate implant placement in interior teeth with facial bone defect using autogenous tooth bone made by extracted tooth can be an acceptable method compared with xenogenic bone.

2. The stability of horizontal bone in the level $0 \mathrm{~mm}$, $3 \mathrm{~mm}$ and $6 \mathrm{~mm}$ of the implant facial part was almost the between the autogenous tooth bone and the xenogenic bone at the 6 months and 12 months follow-up.

3. No matter using autogenous tooth bone or xenogenous bone, the horizontal bone loss at the first or the latter 6 months was almost the same in the level $0 \mathrm{~mm}, 3 \mathrm{~mm}$ and $6 \mathrm{~mm}$ of the implant facial part.

4. No matter what the follow-up period is and bone graft material used, the horizontal bone loss at the level of $6 \mathrm{~mm}$ was much less than the level of $0 \mathrm{~mm}$ and $3 \mathrm{~mm}$ in the facial of the implant.

5. Patient feel better when using the autogenous tooth bone comparing with the xenogenic bone.

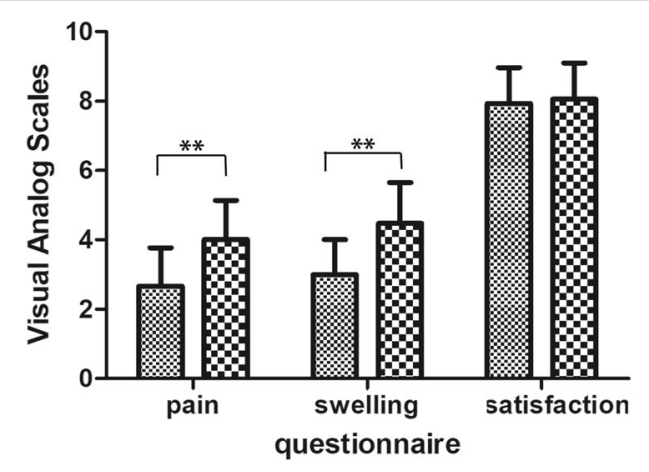

$m$ autogenous tooth bone

xenogenic bone

Fig. 8 The value in pain, swelling and satisfaction in the group of autogenous tooth bone and xenogenic bone 


\section{Supplementary information}

Supplementary information accompanies this paper at https://doi.org/10. 1186/s12903-019-0970-7.

Additional file 1. Questionnaire. Table 2 and Fig. 8. The data were based on the questionnaire about the pain, swelling and satisfaction about the surgery. And the quantitative value was based on the Visual Analog Scales (VAS 0-10).

\section{Abbreviations}

atuoBT: autogenous Tooth Bone; CBCT: Cone-Beam Computed Tomography; MBL: Marginal Bone Level; VAS: Visual Analog Scales; xenoB: xenogenic Bone

\section{Acknowledgements}

Thanks for the patients who participated the follow-up.

\section{Authors' contributions}

DW and WXH contributed to operation of the surgical proceduce. JC and YHC contributed to the design the surgical proceduce. $\mathrm{LZ}$ and $\mathrm{JCL}$ contributed to date collection and drafting article. All authors read and approved the final manuscript.

\section{Funding}

The study was financially supported by the National Natural Science Foundation of China (NSFC) (No.81771126), Fujian provincial healthy and family planning commission program (No.2015-CX-30) and Science Foundation of Fujian Province (No.2019 J01319). These funding bodies had no role in the design of the study, the collection, analysis and interpretation of data and in writing the manuscript.

\section{Availability of data and materials}

The datasets used and analysed during the current study are available from the corresponding author on reasonable request.

\section{Ethics approval and consent to participate}

The study protocol was evaluated and approved by the Institutional Ethics Committee of the School of Stomatology, Fujian Medical University (Ref. [2015] NO.103). All procedures performed in studies involving human participants were in accordance with the ethical standards of the institutional and/or national research committee and with the 1964 Helsink declaration and its later amendments or comparable ethical standards. All patients provided written informed consent.

\section{Consent for publication}

Not applicable.

\section{Competing interests}

The authors declare that they have no competing interests.

\section{Author details}

Department of Oral Implantology, Affiliated Stomatological Hospital of Fujian Medical University, Fuzhou 350002, Fujian, China. ${ }^{2}$ Department of Stomatology, Xiamen branch, Zhongshan hospital, Fudan university, Xiamen 361000, Fujian, China. ${ }^{3}$ Department of Stomatology, Zhangzhou Affiliated Hospital of Fujian Medical University, Zhangzhou 363000, Fujian, China.

Received: 27 September 2019 Accepted: 22 November 2019

\section{Published online: 02 December 2019}

\section{References}

1. Schulte W, Heimke G. The Tubinger immediate implant. Die Quintessenz. 1976;27:17-23.

2. Kan JYK, Rungcharassaeng K, Deflorian M, et al. Immediate implant placement and provisionalization of maxillary anterior single implants. Periodontology 2000. 2018;77:197-212. https://doi.org/10.1111/prd.12212.

3. Cassetta M, Perrotti V, Calasso $\mathrm{S}$, et al. Bone formation in sinus augmentation procedures using autologous bone, porcine bone, and a 50 50 mixture: a human clinical and histological evaluation at 2 months. Clin Oral Implants Res. 2015;26:1180-4. https://doi.org/10.1111/clr.12423.
4. Zucchelli G, Sharma P, Mounssif I. Esthetics in periodontics and implantology Periodontology 2000. 2018;77:7-18. https://doi.org/10.1111/prd.12207.

5. Aghaloo TL, Misch C, Lin GH, et al. Bone augmentation of the edentulous maxilla for implant placement: a systematic review. Int J Oral Maxillofac Implants. 2016;31(Suppl):s19-30. https://doi.org/10.11607/jomi.16suppl.g1.

6. Schmitt $\mathrm{CM}$, Doering $\mathrm{H}$, Schmidt $\mathrm{T}$, et al. Histological results after maxillary sinus augmentation with Straumann(R) BoneCeramic, Bio-Oss(R), Puros(R), and autologous bone. A randomized controlled clinical trial. Clin Oral Implants Res. 2013;24:576-85. https://doi.org/10.1111/j.1600-0501.2012.02431.x.

7. Kim YK, Kim SG, Um IW, et al. Bone grafts using autogenous tooth blocks: a case series. Implant Dent. 2013;22:584-9. https//doi.org/10.1097//D.00000000000000011.

8. Jeong Kl, Kim SG, Kim YK, et al. Clinical study of graft materials using autogenous teeth in maxillary sinus augmentation. Implant Dent. 2011;20: 471-5. https://doi.org/10.1097/ID.0b013e3182386d74.

9. Lee JY, Kim YK, Yi YJ, et al. Clinical evaluation of ridge augmentation using autogenous tooth bone graft material: case series study.J Korean Assoc. Oral Maxillofac Surg. 2013;39:156-60. https://doi.org/10.5125/jkaoms.2013.39.4.156.

10. Schwarz F, Hazar D, Becker K, et al. Efficacy of autogenous tooth roots for lateral alveolar ridge augmentation and staged implant placement. A prospective controlled clinical study. J Clin Periodontol. 2018;45:996-1004. https://doi.org/10.1111/jcpe.12977.

11. Kim YK, Kim SG, Yun PY, et al. Autogenous teeth used for bone grafting: a comparison with traditional grafting materials. Oral Surg Oral Med Oral Pathol Oral Radiol. 2014;117:e39-45. https://doi.org/10.1016/j.o0oo.2012.04.018.

12. Kim YK, Lee JH, Um IW, et al. Guided bone regeneration using demineralized dentin matrix: long-term follow-up. J Oral Maxillofac Surg. 2016;74:515.e511-9. https://doi.org/10.1016/j.joms.2015.10.030.

13. Gual-Vaques P, Polis-Yanes C, Estrugo-Devesa A, et al. Autogenous teeth used for bone grafting: a systematic review. Med Oral Patol Oral Cir Bucal. 2018:23:e112-9. https://doi.org/10.4317/medoral.22197.

14. Buser D, Chappuis V, Belser UC, et al. Implant placement post extraction in esthetic single tooth sites: when immediate, when early, when late? Periodontology 2000. 2017;73:84-102. https://doi.org/10.1111/prd.12170.

15. Schropp L, Wenzel A, Kostopoulos L, et al. Bone healing and soft tissue contour changes following single-tooth extraction: a clinical and radiographic 12-month prospective study. Int J Periodontics Restorative Dent. 2003:23:313-23.

16. Milinkovic I, Cordaro L. Are there specific indications for the different alveolar bone augmentation procedures for implant placement? A systematic review. Int J Oral Maxillofac Surg. 2014;43:606-25. https://doi.org/10.1016/j.jom.2013.12.004.

17. Guiol J, Campard G, Longis J, et al. Anterior mandibular bone augmentation techniques. Literature review. Revue de stomatologie de chirurgie maxillo-faciale et de chirurgie orale. 2015;116:353-9. https://doi.org/10.1016/j.revsto.2015.10.003.

18. Jun SH, Ahn JS, Lee Jl, et al. A prospective study on the effectiveness of newly developed autogenous tooth bone graft material for sinus bone graft procedure. J Adv Prosthodont. 2014;6:528-38. https:/doi.org/10.4047/jap.2014.6.6.528.

19. Nampo T, Watahiki J, Enomoto A, et al. A new method for alveolar bone repair using extracted teeth for the graft material. J Periodontol. 2010;81: 1264-72. https://doi.org/10.1902/jop.2010.100016.

20. Prasad M, Butler WT, Qin C. Dentin sialophosphoprotein in biomineralization. Connect Tissue Res. 2010;51:404-17. https://doi.org/10. 3109/03008200903329789.

21. Kim YK, Kim SG, Oh JS, et al. Analysis of the inorganic component of autogenous tooth bone graft material. J Nanosci Nanotechnol. 2011:11:7442-5.

22. Amato F, Polara G, Spedicato GA. Tissue dimensional changes in singletooth immediate extraction implant placement in the esthetic zone: a retrospective clinical study. Int J Oral Maxillofac Implants. 2018;33:439-47. https://doi.org/10.11607/jomi.6146.

23. Mazzocco F, Jimenez D, Barallat $L$, et al. Bone volume changes after immediate implant placement with or without flap elevation. Clin Oral Implants Res. 2017;28:495-501. https://doi.org/10.1111/clr.12826.

24. Kinaia BM, Shah M, Neely AL, et al. Crestal bone level changes around immediately placed implants: a systematic review and meta-analyses with at least 12 months' follow-up after functional loading. J Periodontol. 2014 85:1537-48. https://doi.org/10.1902/jop.2014.130722.

25. AlKudmani $\mathrm{H}$, Al Jasser $\mathrm{R}$, Andreana $\mathrm{S}$. Is bone graft or guided bone regeneration needed when placing immediate dental implants? A systematic review. Implant Dent. 2017;26:936-44. https://doi.org/10.1097/id.0000000000000689.

26. Velasco-Ortega E, Wojtovicz E, Espana-Lopez A, et al. Survival rates and bone loss after immediate loading of implants in fresh extraction sockets (single gaps). A clinical prospective study with 4 year follow-up. Med Oral Patol Oral Cir Bucal. 2018;23:e230-6. https://doi.org/10.4317/medoral.21651. 
27. Iorio-Siciliano V, Matarasso R, Guarnieri R, et al. Soft tissue conditions and marginal bone levels of implants with a laser-microtextured collar: a 5-year, retrospective, controlled study. Clin Oral Implants Res. 2015;26:257-62. https://doi.org/10.1111/clr.12518.

28. Iorio-Siciliano V, Marenzi G, Blasi A, et al. Influence of platform-switched, laser-microtextured implant on marginal bone level: a 24-month case series study. Int J Oral Maxillofac Implants. 2016;31:162.

29. Terashima A, Takayanagi H. Overview of Osteoimmunology. Calcif Tissue Int. 2018;102:503-11. https://doi.org/10.1007/s00223-018-0417-1.

30. Walsh MC, Takegahara N, Kim H, et al. Updating osteoimmunology: regulation of bone cells by innate and adaptive immunity. Nature reviews. Rheumatology. 2018;14:146-56. https://doi.org/10.1038/nrrheum.2017.213.

31. Blakney AK, Swartzlander MD, Bryant SJ. The effects of substrate stiffness on the in vitro activation of macrophages and in vivo host response to poly(ethylene glycol)-based hydrogels. J Biomed Mater Res A. 2012;100: 1375-86. https://doi.org/10.1002/jbm.a.34104.

32. Um IW, Kim YK, Mitsugi M. Demineralized dentin matrix scaffolds for alveolar bone engineering. J Indian Prosthodont Soc. 2017;17:120-7. https:// doi.org/10.4103/jips.jps_62_17.

\section{Publisher's Note}

Springer Nature remains neutral with regard to jurisdictional claims in published maps and institutional affiliations.

Ready to submit your research? Choose BMC and benefit from:

- fast, convenient online submission

- thorough peer review by experienced researchers in your field

- rapid publication on acceptance

- support for research data, including large and complex data types

- gold Open Access which fosters wider collaboration and increased citations

- maximum visibility for your research: over $100 \mathrm{M}$ website views per year

At BMC, research is always in progress.

Learn more biomedcentral.com/submissions 